\title{
Viscosity correlation development for corn oil biodiesel- diesel fuel blends
}

\author{
Mert Gülüm*, Atilla Bilgin \\ Department of Mechanical Engineering, Karadeniz Technical University, Trabzon, 61080, Turkey
}

\begin{abstract}
In this study, the lowest dynamic viscosity corn oil biodiesel was produced using methanol as alcohol and potassium hydroxide as catalyst by means of transesterification reaction. Dynamic viscosities of produced corn oil biodiesel and its blends with diesel fuel at different temperatures were measured according to international standard. Effects of temperature and biodiesel content in blend on changes of their dynamic viscosities were examined. Changes were described by means of regression models such as two-term exponential model and three-term logarithmic model. Constants and regression coefficients of these models were computed and reported in tables.
\end{abstract}

Keywords: Canola oil biodiesel, transesterification, viscosity, two-term exponential model, three-term logarithmic model

\section{Introduction}

Rapid growth in population coupling with industrial and technological development is leading to towards the depletion of limited fossil fuel resources of the world. Currently, researches are progressively more directed towards exploration of alternative renewable fuels such as bio-ethanol, biodiesel etc. [1]. Biodiesel is becoming popular in the markets of developed countries as well as developing ones [2]. For example, diesel fuel blended with $20 \%$ of biodiesel produced by the soybean oil is available in the US market now [3]. While biodiesel faces some technical challenges such as increasing $\mathrm{NO}_{\mathrm{x}}$ exhaust emissions and kinematic viscosities, advantages of biodiesel compared to diesel fuel include reduction of most regulated exhaust emissions such as $\mathrm{CO}, \mathrm{HC}$ and smoke, improved biodegradability, low or no sulfur content, inherent lubricity, higher flash point temperature, domestic origin and renewability [4]. In addition, biodiesel is completely miscible with diesel fuel, allowing the blending of these two fuels in any proportion. However, differences in the chemical nature of biodiesel (mixture of mono-alkyl ester of saturated and unsaturated long chain fatty acids) and diesel fuel (mixture of paraffinic, naphthenic and aromatic hydrocarbons) result in differences in their basic properties such as viscosity, density, cetane number, higher heating value etc., affecting engine performance, combustion characteristics and pollutant emissions. Given the difficulty of obtaining these basic properties of the blends by measurement, the ability to calculate them using regression models is very useful [5], [6]. In literature, many researchers have already suggested lots of regression models as a function of biodiesel content, temperature, chemical structure etc. to estimate fuel properties such as kinematic viscosity, density, cetane number, flash point temperature, distillation curves etc. as following: Qi and Lee [5] determined distillation curves, cold filter plugging points, cloud points, acid values, sulfur contents and oxidation stabilities of soybean biodieseldiesel blends according to the corresponding standards, and the influences of biodiesel content on these blends' properties were evaluated. Kay's mixing rule was used for predicting the properties. Ebna et al. [7] investigated densities, dynamic viscosities and higher heating values of waste cooking palm oil methyl

\footnotetext{
* Manuscript received January 21, 2017; revised June 21, 2017.

Corresponding author. Tel.: +90 46237741 30; E-mail address: mertgulumm@gmail.com

doi: $10.12720 /$ sgce.6.3.165-170
} 
ester and its blends with No. 2 diesel fuel under varying temperature. Based on the experimental results, regression correlations such as Kay's mixing rule and Grunberg-Nissan mixing rule have been proposed for estimating these fuel properties. Gülüm and Bilgin [8] investigated variations of densities, flash point temperatures and higher heating values of corn oil biodiesel-Ultra Force Euro diesel fuel blends. The authors also proposed new one- and two-dimensional models to predict these fuel properties.

In this study, (1) the minimum dynamic viscosity corn oil biodiesel was produced using methanol $\left(\mathrm{CH}_{3} \mathrm{OH}\right)$ and potassium hydroxide $(\mathrm{KOH}),(2)$ the produced biodiesel was blended with commercially available diesel fuel at the volume ratios of 5, 10, 15, 20, 25, 50 and 75\%, (3) kinematic viscosities of the biodiesel-diesel fuel blends were measured at different temperatures $\left(10,20,30\right.$ and $\left.40^{\circ} \mathrm{C}\right)$ according to international standard, and (4) regression models were proposed for viscosity-blending ratio and viscosity-temperature relationships.

\section{Materials and Methods}

\subsection{Materials}

To produce biodiesel by basic catalyzed transesterification, refined corn oil (purchased from a market), methanol (Merck, 99.8\% purity) and potassium hydroxide (Merck, pure grade) were used.

\subsection{Biodiesel production}

The parameters of transesterification reaction were determined as $1.1 \%$ catalyst $(\mathrm{KOH})$ concentration, $60^{\circ} \mathrm{C}$ reaction temperature, 60 minute reaction time and 9:1 alcohol/oil molar ratio to produce the minimum dynamic viscosity corn oil biodiesel in a master thesis done by Gülüm [9]. Details of biodiesel production were given in [8], [9].

\subsection{Density measurement}

The densities of the biodiesel-diesel fuel blends were determined by means of Eq. (1) and measurements in accordance with ISO 4787 standard:

$$
\rho_{\text {biodiesel }}=\frac{\mathrm{m}_{\text {total }}-\mathrm{m}_{\text {pycnometer }}}{\mathrm{m}_{\text {water }}} \rho_{\text {water }}
$$

where $\rho$ and $\mathrm{m}$ represent density and mass, respectively. The density measurements were conducted three times for each sample and the results were averaged. Details of the measurements were given in $[8,9]$.

\subsection{Dynamic viscosity measurement}

The dynamic viscosities were determined in accordance with DIN 53015 standard by using Eq. (2) and making measurements by means of the Haake Falling Ball Viscometer, Haake Water Bath and stopwatch:

$$
\mu_{\text {biodiesel }}=\mathrm{K}_{\text {ball }}\left(\rho_{\text {ball }}-\rho_{\text {biodiesel }}\right) \mathrm{t}
$$

where $\mu_{\text {biodiesel }}$ is dynamic viscosity, $\mathrm{K}$ is coefficient of the viscometer ball, and $\mathrm{t}$ is falling time of the ball moving between two horizontal line marked on viscometer tube at limit velocity. $K_{\text {ball }}$ and $\rho_{\text {ball }}$ are $0.057 \mathrm{mPa} . \mathrm{s} . \mathrm{cm}^{3} / \mathrm{g} / \mathrm{s}$ and $2.2 \mathrm{~g} / \mathrm{cm}^{3}$, respectively. The viscosity measurements were also conducted three times for each sample and the results were averaged.

In this study, densities and viscosities were measured in Internal Combustion Engines Laboratory in the Mechanical Engineering Department at Karadeniz Technical University. The fatty acid methyl ester compositions of the produced biodiesel were determined in Science Research and Application Center at Mustafa Kemal University. Moreover, other fuel properties such as flash point temperature, cold filter 
plugging point temperature and higher heating value were measured in the Prof. Dr. Saadettin GÜNER Fuel Research and Application Center at Karadeniz Technical University. Table 1 lists these fuel properties with EN 14214 and ASTM D 6751 standard values, and Table 2 shows fatty acid compositions of the produced biodiesel and its calculated average molecular mass and typical formula.

Table 1. Some fuel properties of diesel fuel and produced biodiesel, and corresponding standard values for biodiesel

\begin{tabular}{|c|c|c|c|c|c|}
\hline Properties & Units & $\mathrm{B} 100$ & $\mathrm{D}$ & EN14214 & $\begin{array}{c}\text { ASTM- } \\
\text { D6751 }\end{array}$ \\
\hline $\begin{array}{l}\text { Dynamic viscosity } \\
\left(\text { at } 40^{\circ} \mathrm{C}\right)\end{array}$ & mPa.s & 3.489 & 2.233 & $3.50-5.00$ & $1.90-6.0$ \\
\hline Density (at $15^{\circ} \mathrm{C}$ ) & $\mathrm{kg} / \mathrm{m}^{3}$ & 877.94 & 833.33 & $860-900$ & 4 \\
\hline Flash point ${ }^{1}$ & ${ }^{\circ} \mathrm{C}$ & 171 & 63 & $101 \leq$ & $130 \leq$ \\
\hline $\begin{array}{l}\text { Cold filter plugging } \\
\text { point }^{2}\end{array}$ & ${ }^{\circ} \mathrm{C}$ & -4.0 & -6.0 & $\begin{array}{l}<+5 \\
-15<\end{array}$ & 4 \\
\hline Higher heating value ${ }^{3}$ & $\mathrm{~kJ} / \mathrm{kg}$ & 39947 & 45950 & 4 & 4 \\
\hline
\end{tabular}

${ }^{1}$ Measured in EN ISO 3679.
${ }^{2}$ Measured in EN 116.
${ }^{3}$ Measured in DIN 51900-2.
${ }^{4}$ Not specified.

Table 2. Fatty acid methyl ester composition of the produced biodiesel

\begin{tabular}{lc}
\hline Fatty acid $^{1}$ & Mass, \% \\
\hline Palmitic (C16:0) & 20.278 \\
Oleic (C18:1) & 47.184 \\
Linoleic (C18:2) & 29.575 \\
$\alpha$-Linolenic acid (C18:3) & 1.077 \\
Arachidic (C20:0) & 0.972 \\
Gadoleic acid (C20:1) & 0.445 \\
Behenic (C22:0) & 0.470 \\
Average molecular mass & $291.270^{2}$ \\
Typical formula & $\mathrm{C}_{18.66} \mathrm{H}_{35.13} \mathrm{O}_{2}{ }^{2}$ \\
${ }^{1}$ Determined using gas chromatography device. \\
${ }^{2}$ Calculated from fatty acid distribution.
\end{tabular}

\section{Result and Discussion}

Fig. 1 shows changes of dynamic viscosities of corn oil biodiesel-diesel fuel blends with respect to biodiesel fraction for varying temperature. In this figure, the points correspond to the viscosity values measured by the authors for studied temperatures and biodiesel fractions, while the lines are plots of curve fit equation. It is clear from this figure that all the blends follow the same trend, i.e., viscosities of the blends increase with increasing biodiesel fractions for studied temperatures, as expected. In order to characterize these variations, two-term exponential model was fitted to the experimental data:

$$
\mu=\mu(X)=a+b\left(1-e^{-c x}\right)
$$

where $\mu$ is dynamic viscosity (mPa. s), a, b and c are regression constants and $\mathrm{X}$ is biodiesel fraction. 


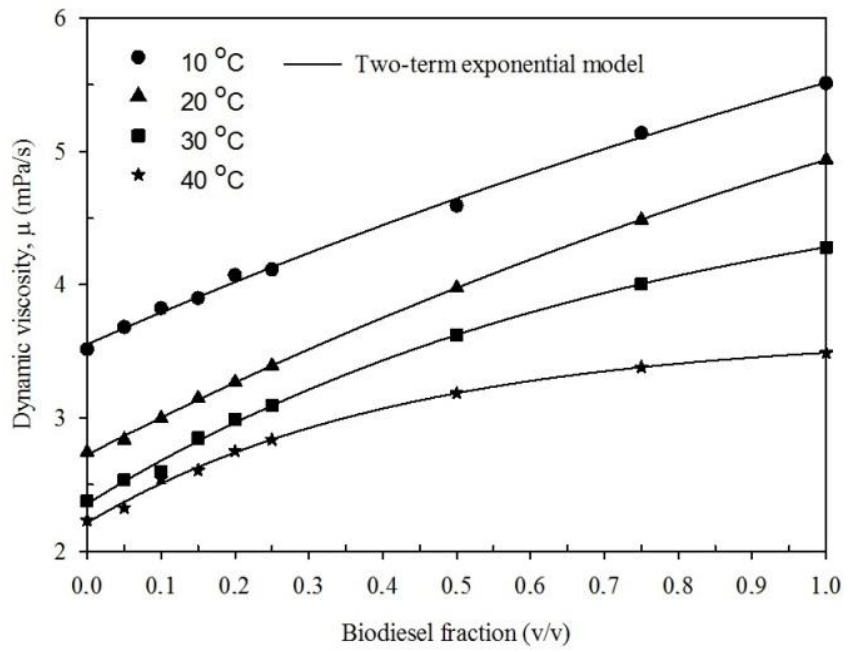

Fig. 1. Variation of dynamic viscosity with respect to biodiesel fraction in blend.

Table 3 lists the measured and calculated dynamic viscosities from Eq. (3), relative errors between them, regression constants and correlation coefficients (R). For the blends, the maximum relative error is $3.1736 \%$ with the lowest $\mathrm{R}$ value of 0.9986 . Therefore, the two-term exponential model is suitable fit for the changes of dynamic viscosities versus biodiesel fractions.

Table 3. For different temperatures, the measured and calculated viscosities from Eq. (3), errors between measured and calculated viscosities, regression constants and correlation coefficients

\begin{tabular}{|c|c|c|c|c|c|c|c|c|c|c|c|c|c|}
\hline \multirow{3}{*}{$\begin{array}{l}\text { Tem. } \\
\left({ }^{\circ} \mathrm{C}\right)\end{array}$} & \multicolumn{9}{|c|}{ Measured, $\mu$ (mPa.s) } & \multirow{2}{*}{\multicolumn{3}{|c|}{ Regression constants }} & \multirow{3}{*}{$\mathrm{R}$} \\
\hline & \multicolumn{9}{|c|}{ Biodiesel fraction, X (\%) } & & & & \\
\hline & 0 & 5 & 10 & 15 & 20 & 25 & 50 & 75 & 100 & $\mathrm{a}$ & $\mathrm{b}$ & $\mathrm{c}$ & \\
\hline 10 & 3.514 & 3.681 & 3.824 & 3.899 & 4.072 & 4.114 & 4.593 & 5.137 & 5.512 & 3.5520 & 5.3330 & 0.4593 & 0.9987 \\
\hline 20 & 2.743 & 2.836 & 2.997 & 3.148 & 3.270 & 3.392 & 3.976 & 4.487 & 4.939 & 0 & 910 & 287 & 0.9999 \\
\hline 30 & 2.376 & 2.538 & 2.598 & 2.849 & 2.992 & 3.092 & 3.623 & 4.006 & 4.281 & 2.3570 & 2.6400 & 1.3070 & 0.9988 \\
\hline 40 & 2.233 & 2.326 & 2.546 & 2.608 & 2.753 & 2.838 & 3.186 & 3.381 & 3.489 & 2.2150 & 1.4120 & 2.3290 & 0.9986 \\
\hline
\end{tabular}

Table 3. (Continued)

\begin{tabular}{ccccccccc}
\hline \multicolumn{7}{c}{ Belative errors } \\
\hline \multicolumn{7}{c}{ Biodiesel fraction, X (\%) } \\
\hline 0 & 5 & 10 & 15 & 20 & 25 & 50 & 75 & 100 \\
\hline 1.0814 & 0.2152 & 0.8524 & 0.2064 & 1.2755 & 0.4014 & 1.1598 & 0.6020 & 0.0904 \\
0.6927 & 1.0100 & 0.1541 & 0.4123 & 0.1547 & 0.0156 & 0.0076 & 0.0384 & 0.0263 \\
0.7997 & 0.5513 & 3.1736 & 0.7723 & 0.9268 & 0.0279 & 0.0170 & 0.0106 & 0.0359 \\
0.8061 & 1.9009 & 1.4781 & 0.8947 & 0.4438 & 0.0071 & 0.0108 & 0.0050 & 0.0138 \\
\hline
\end{tabular}

The effects of temperature on dynamic viscosities of corn oil biodiesel-diesel fuel blends are illustrated in Fig. 2. It is clear from this figure that viscosities of the all blends follow the same trend: as temperature is increased, viscosities decrease, as expected. The experimental data were correlated with the three-term logarithmic model by applying the least squares method as:

$$
\mu=\mu(T)=a+b \operatorname{In} T+c(\operatorname{InT})^{2}
$$

where $\mathrm{T}$ is temperature $\left({ }^{\circ} \mathrm{C}\right), \mathrm{a}, \mathrm{b}$ and $\mathrm{c}$ are regression constants. 


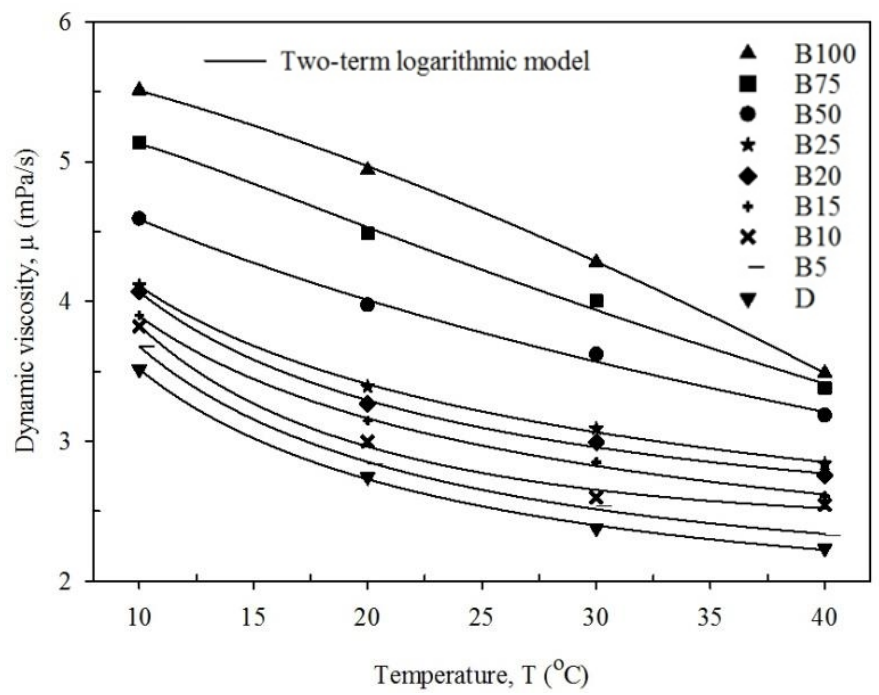

Fig. 2. Variation of dynamic viscosity with respect to temperature.

The measured and calculated dynamic viscosities from Eq. (4), relative errors between them, regression constants and correlation coefficients are given in Table 4. For the blends, the maximum relative error and the lowest $\mathrm{R}$ value were computed as $2.0978 \%$ and 0.9977 . These results and Fig. 2 indicate that the relation between dynamic viscosities with temperature is found to be proper expressed by the three-term logarithmic model.

Table 4. For different biodiesel fractions, the measured and calculated viscosities from Eq. (4), errors between measured and calculated viscosities, regression constants and correlation coefficients

\begin{tabular}{|c|c|c|c|c|c|c|c|c|c|c|c|c|}
\hline \multirow{3}{*}{$\begin{array}{c}\text { Biodiesel } \\
\text { fraction } \\
\mathrm{X}(\%)\end{array}$} & \multirow{2}{*}{\multicolumn{4}{|c|}{$\begin{array}{c}\text { Measured, } \mu(\mathrm{mPa} . \mathrm{s}) \\
\text { Temp., } \mathrm{T}\left({ }^{\circ} \mathrm{C}\right)\end{array}$}} & \multirow{2}{*}{\multicolumn{3}{|c|}{ Regression constants }} & \multirow{3}{*}{$\mathrm{R}$} & \multicolumn{4}{|c|}{ Relative errors } \\
\hline & & & & & & & & & \multicolumn{4}{|c|}{ Temp., T $\left({ }^{\circ} \mathrm{C}\right)$} \\
\hline & 10 & 20 & 30 & 40 & $\mathrm{a}$ & $\mathrm{b}$ & $\mathrm{c}$ & & 10 & 20 & 30 & 40 \\
\hline 0 & 3.514 & 2.743 & 2.376 & 2.233 & 8.1650 & -2.6960 & 0.2942 & 0.9996 & 0.0854 & 0.5177 & 0.9554 & 0.4389 \\
\hline 5 & 3.681 & 2.836 & 2.538 & 2.326 & 8.6540 & -2.9060 & 0.3236 & 0.9995 & 0.0706 & 0.5818 & 0.9614 & 0.4987 \\
\hline 10 & 3.824 & 2.997 & 2.598 & 2.546 & 9.7930 & -3 & 9 & 0.9977 & 0 & 1. & 2.0978 & 44 \\
\hline 15 & 3.899 & 3.148 & 2.849 & 2.608 & 7.6610 & -2.0810 & 0.1937 & 0.9994 & 0.0692 & 0.5464 & 0.8810 & 0.4716 \\
\hline 20 & 4.072 & 3.270 & 2.992 & 2.753 & 8.4380 & -2.4980 & 0.2606 & 0.9 & 0.1031 & 0.7156 & 1.1865 & 0.5957 \\
\hline 25 & 4.114 & 3.392 & 3.092 & 2.838 & 7.4590 & -1.79 & 0.1477 & 0.9993 & 0.0 & 0.5366 & 0.8441 & 0.4581 \\
\hline 50 & 4.593 & 3.976 & 3.623 & 3.186 & 4.8870 & 0.4 & -0 . & 0.9978 & 0.1 & 0.8954 & 1.4380 & 0.8004 \\
\hline 75 & 5.137 & 4.487 & 4.006 & 3.381 & 3.3780 & 2.0090 & -0.5 & 0.9978 & 0.1304 & 1.0096 & 1.6201 & 0.9613 \\
\hline 100 & 5.512 & 4.939 & 4.281 & 3.489 & 0.6314 & 4.3360 & -0.9637 & 0.9991 & 0.1089 & 0.6742 & 1.1726 & 0.6735 \\
\hline
\end{tabular}

\section{Conclusion}

In this study, corn oil biodiesel having minimum viscosity was produced by means of transesterification reaction. The produced biodiesel was blended with diesel fuel at the different volume ratios $(5,10,15,20,25,50$ and $75 \%)$. For blends, pure biodiesel and diesel fuel, two-term exponential and three-term logarithmic correlations were developed to represent changes of dynamic viscosities with respect to temperature and biodiesel fraction, respectively. According to results, these exponential and logarithmic models with the max. relative errors and lowest correlation coefficients $(3.1755 \%-0.9986$ and $3.1755 \%-0.9986$ ) are quite suitable to represent these changes.

In the light of this work, researchers could try to develop new or general models to estimate other fuel properties such as heating value, cetane number, acid value etc. of different biodiesel-diesel binary or biodiesel-diesel-alcohol ternary blends for future studies. 


\section{Acknowledgement}

The authors express their gratitude to Karadeniz Technical University Scientific Research Projects Fund for financial support received (Project No: 9745).

\section{References}

[1] Rashid U, Anwar F. Production of biodiesel through optimized alkaline-catalyzed transesterification of rapeseed oil. Fuel, 2008; 87:265-273.

[2] Wang Y, Ou S, Liu P, Xue F, Tang S. Comparison of two different processes to synthesize biodiesel by waste cooking oil. Journal of Molecular Catalysis A: Chemical, 2006; 252:107-112.

[3] Körbitz W. Biodiesel production in Europe and North America, an encouraging prospect. Renewable Energy, 1999; 16:10781083.

[4] Knothe G, Steidley K. Kinematic viscosity of fatty acid methyl esters: Prediction, calculated viscosity contribution of esters with unavailable data, and carbon-oxygen equivalents. Fuel, 2011; 90:3217-3224.

[5] Qi D, Lee C. Influence of soybean biodiesel content on basic properties of biodiesel-diesel blends. Journal of the Taiwan Institute of Chemical Engineers, 2014; 45:504-507.

[6] Aydın F, Kafadar A, Erdogan S, Saydut A, Kaya C. The basic properties of transesterified corn oil and biodiesel-diesel blends. Energy Sources, Part A: Recovery, Utilization, and Environmental Effects, 2011; 33:745-751.

[7] Fahd MEA., Lee PS., Chou SK., Wenming Y, Yap C. Experimental study and empirical correlation development of fuel properties of waste cooking palm biodiesel and its diesel blends at elevated temperatures. Renewable Energy, 2014; 68:282288.

[8] Gülüm M, Bilgin A. Density, flash point and heating value variations of corn oil biodiesel-diesel fuel blends. Fuel Processing Technology, 2015; 134 456-464.

[9] Gülüm M. Experimental investigation of the effect of various production parameters on the some fuel properties of produced biodiesels from corn and hazelnut oils. Master's thesis, Department of Mechanical Engineering, Karadeniz Technical University, Trabzon, Turkey, 2014. 